\title{
Evaluation of Alkali-Silica Reactivity Using Aggregate Geology, Expansion Limits of Mortar Bars and Concrete Prisms, and Kinetic Model
}

\author{
Mohammad S. Islam ${ }^{1,2} \&$ Nader Ghafoori ${ }^{1}$ \\ ${ }^{1}$ Department of Civil and Environmental Engineering and Construction, University of Nevada, Las Vegas, USA \\ ${ }^{2}$ Present Address: Department of Mathematics and Statistics, McMaster University, Canada
}

Correspondence: Mohammad S. Islam, Department of Mathematics and Statistics, McMaster University, ON, L8S 4L8, Canada. Tel: 1-289-933-4300. E-mail: mohammis@mcmaster.ca

Received: December 31, 2012 Accepted: February 16, 2013 Online Published: March 15, 2013

doi:10.5539/jmsr.v2n2p103 URL: http://dx.doi.org/10.5539/jmsr.v2n2p103

\begin{abstract}
The main objective of this study was to evaluate and classify the alkali-silica reactivity of thirteen aggregate groups using aggregate geology, and early and extended expansion limits of mortar bars and concrete prisms submerged in the $1 \mathrm{~N} \mathrm{NaOH}$ for 4,8 and 13 weeks. The previously suggested ASR kinetic model, known as Kolmogorov-Avrami-Mehl-Johnson (K-A-M-J) model, was fitted with the prism expansion data over the test durations of 4,8 and 13 weeks, and a new failure criteria was developed to better predict the degree of reactivity of the trial aggregates. The ASR classifications of the investigated aggregates evaluated by the failure criteria of alkali-cured prisms and ASR kinetic model were in good agreement with the results generated from the failure limits of mortar bars and from aggregate potential reactivity based on aggregate type.
\end{abstract}

Keywords: Alkali-silica reactivity, expansion, mortar bar, prism, failure criteria, aggregate mineralogy

\section{Introduction}

Portland cement concrete is the most widely-used construction material in the world. The reactions between aggregates and binding agents (cement and other cementitious materials) in concrete are extremely complex. Many natural aggregates contain a quantity of amorphous silica, which both react with the alkalis of the mixture ( $\mathrm{Na}$ and $\mathrm{K}$, which usually come from cementitious materials). This interaction is widely known as alkali-silica reaction (ASR). The reaction can cause deterioration expansion in concrete, and result in significant damages to concrete structures.

The reactivity of an aggregate primarily depends on its geological background, internal structure and physical characteristics, as well as specimen size. The form of silica in aggregate determines whether a siliceous aggregate is reactive or not. The silica of reactive aggregate is primarily accountable to form ASR in concrete. The reactivity of silica depends on the crystalline structure of the silica rather than its chemical compositions. Damaging reactions can only occur if the aggregate contains sufficient quantities of the reactive silica. However, the volume of reactive silica needed to produce deleterious effects is very small (Swamy, 1992), and the quantity varies on the rock types and reactive minerals (ACI, 1998). Table 1 outlines major rock types prone to alkali-silica reaction.

Various standard tests are available to evaluate the alkali-silica reactivity of an aggregate. Among them, the concrete prism test (ASTM C 1293) and accelerated mortar bar test (ASTM C 1260) are popular throughout the world. In the ASTM C 1260 test, the specimens are immersed in $1 \mathrm{~N} \mathrm{NaOH}$ solution at $80^{\circ} \mathrm{C}$ for a minimum of 2 weeks. A range of expansion limits of mortar bars have been suggested to evaluate potentially harmful reactions, and among them, a maximum permissible expansion of $0.10 \%$ at 2 weeks is the most standard citation (Tauma, Fowler \& Carrasquillo, 2001). Several researchers (Grattan-Bellew, 1990; DeMerchant \& Soles, 1993) also suggested different expansion limits in detecting aggregate reactivity for varying aggregate mineralogy, namely, $0.10 \%$ for reactive siliceous limestone, $0.20 \%$ for greywackes, and $0.15 \%$ for the other types of aggregates. Past investigations demonstrated that the 2-week failure limit of $0.10 \%$ were not capable of predicting the actual alkali-silica reactivity of some aggregates (Jin, 1998; Folliard, Thomas, Fournier, Kurtis, \& Ideker, 2006; Lenke 
\& Malvar, 2006). Considering the multi-laboratory coefficient of variation in the experimental results, the aggregate generating more than $0.15 \%$ expansion under the $1 \mathrm{~N} \mathrm{NaOH}$ solution at 2 weeks would be classified potentially reactive (Rogers, 1993; Rogers \& Hooton, 1993). In order to increase the reliability of the test, Johnston (1994) and Johnston, Stokes, Fournier and Surdahl (2004) suggested to extend test duration from 2 to 4 weeks. Since the expansion development over the immersion age varies among aggregates, the concerns over the 2-week failure limit have led to the additional expansion limits of $0.33 \%$ at 4 weeks and $0.48 \%$ at 8 weeks, proposed by Rogers (1993), and Rogers and Hooton (1993). Islam (2010) proposed that the aggregates producing the 2-, 4- and 8-week ASR-induced expansions of $0.10,0.28$ and $0.47 \%$, respectively, should be considered reactive, and those producing expansions below the three above-mentioned proposed limits can be classified as innocuous. Additionally, aggregates generating the expansions of more than $0.10 \%$ at 2 weeks and less than $0.28 \%$ at 4 weeks and $0.47 \%$ at 8 weeks can be regarded as moderately reactive (Islam \& Ghafoori, 2011; Islam, 2010).

Table 1. Major rock types prone to alkali-silica reaction (Islam \& Ghafoori, 2009)

\begin{tabular}{lll}
\hline Rock Types & Study & ASR \\
\hline \multirow{2}{*}{ Andesite } & Tuthill, 1982; Swamy, 1992; Tauma et al., 2001; Adam, 2004; Thomas, & \\
& $\begin{array}{l}\text { Fournier, Folliard, Ideker, \& Resendez, 2007; Ikeda, Kawabata, Hamada \& } \\
\text { Basalt }\end{array}$ & Reactive \\
Shert & Lanawa, 2008 1994; Adam, 2004; Korkanç \& Tuğrul, 2005 & \\
& Stark, Morgan, Okamoto, \& Diamond, 1993; Lane, 1994; Tauma et al., & Reactive \\
Dacite & 2001 & \\
Dolomite & Tuthill, 1982; Swamy, 1992; Hooton \& Rogers, 1993; Tauma et al., 2001; & Reactive \\
Dolomitic-limestone & Deng et al., 1993; Lane, 1994 & Innocuous \\
Limestone & Thomas et al., 2007 & Reactive \\
Opal & Stark et al.,1993; Jensen, 1996; Tauma et al., 2001 & Innocuous \\
Quartz & Ohama, Demura, \& Kakegawa, 1989; ACI 221, 1998 & Reactive \\
Rhyolite & Tauma et al., 2001; Stark et al., 1993; Lane, 1994; Adam, 2004 & Reactive \\
Silicious aggregate & Hooton \& Rogers, 1993; Fournier, Nkinamubanzi, \& Chevrier, 1994; & Reactive \\
& Berra, Mangialardi, \& Paolini, 1998 &
\end{tabular}

The ASTM C 1293 takes a long time to determine the alkali-silica reactivity of an aggregate. Previous research investigations had dealt with various curing environment, solution type and/or solution strength, and test duration to show the same results of ASTM C 1293 in a shorter span of time to improve the shortcoming of prism test for its test duration. A method involving concrete prisms immersed in $1 \mathrm{~N} \mathrm{NaOH}$ at $80^{\circ} \mathrm{C}(1293 \mathrm{M} 1)$ proved to be reliable in predicting the reactivity of an aggregate (Stark, 2006). The proposed failure criteria of alkali-cured prism of $0.04 \%$ at 4 weeks, recommended by Fournier, Bilodeau and Malhotra (1994), proved to be unreliable for assessing the potential alkali-silica reactivity of some aggregates (Bérubé \& Frenette, 1994; Tauma et al., 2001; Folliard, Ideker, Thomas, \& Fournier, 2005). However, the aggregates producing the 4 -week expansion limit of $0.080 \%$ were classified as highly reactive (Tauma et al., 2001; Folliard et al., 2005).

Johnston, Stokes and Surdahl (2000) and Johnston et al. (2004) first showed the interpretation of mortar expansion with the help of the kinetic-based method, which is known as Kolmogorov-Avrami-Mehl-Johnson (K-A-M-J) model, which is consisted of applying Avrami's equation as shown in Equation 1. The model enlightens nucleation and growth or phase transformation reaction kinetics. Taking the double natural $\log$ of both sides of Equation 1 results in Equation 2 (Johston et al., 2000, 2004).

$$
\operatorname{Exp}_{t}=1+\operatorname{Exp}_{0}-e^{\{-k(t-t) M\}}
$$

Where: $\operatorname{Exp}_{0}$ and $\operatorname{Exp}_{t}$ are the expansions at time $t_{0}$ and $t$, respectively; $t_{0}$ is the first data point in the data set after the initial zero reading; $k$ is expansion rate constant; $M$ is Avrami exponent

$$
Y=X^{*} M+\ln (k)
$$




\section{Where: $Y$ is $\ln \left(\ln \left(1 /\left(1+\operatorname{Exp}_{0}-\operatorname{Exp}_{t}\right)\right)\right)$ and $X$ is $\ln \left(t-t_{o}\right)$}

In the studies conducted by Johnston et al. (2000, 2004), the kinetic model (Equation 2) was fitted with the mortar expansion over the immersion age of 2 weeks, and the values of $\ln (k)$ and $M$ were determined. The study proposed a failure criterion to evaluate alkali-silica reactivity. The aggregates having $\ln (\mathrm{k})$ equals to -6 being the borderline value between the innocuous and reactive aggregates, i.e. aggregates showing $\ln (k)$ value greater than -6 were considered as reactive, and those less than or equal to -6 were classified as innocuous.

The early age failure limit of the accelerated mortar bar test has been broadly reported in assessing aggregate reactivity though it overestimates some innocuous aggregate as reactive. A number of previous investigations on evaluating ASR were mostly confined to the failure criterion of alkali-cured concrete prisms at 4 weeks, which also classified some innocuous aggregates as reactive. The expansion of mortar bars and alkali-cured prisms made with both innocuous and reactive aggregates varied extensively at early age, and the variation decreased with time (Islam, 2010). As such, assessing aggregate for alkali-silica reactivity at the extended ages produced consistent results, when compared to that obtained at early age (Islam, 2010).

\section{Research Significance}

This study extends the previous research investigations by introducing new failure criteria of alkali-cured prisms at the immersion ages of 4, 8 and 13 weeks, and those obtained by the kinetic models at 4, 8 and 13 weeks. The study also highlights the relationship amongst aggregate type, the expansion criteria of mortar bars and alkali-cured prism at early and extended ages, and the kinetic model failure criterion for alkali-cured prisms.

\section{Experimental Program}

The aggregates investigated in this study were acquired from thirteen different quarries. Table 2 shows the identification, rock types, and the chemical constituents of the investigated aggregates. Potential reactivity of each aggregate group based on its mineralogy (Table 1) is also shown in Table 2. ASTM Type V Portland cement with $21 \% \mathrm{SiO}_{2}, 3.6 \% \mathrm{Al}_{2} \mathrm{O}_{3}, 3.4 \% \mathrm{Fe}_{2} \mathrm{O}_{3}, 63.1 \% \mathrm{CaO}, 4.7 \% \mathrm{MgO}, 0.84 \% \mathrm{Na}_{2} \mathrm{O}_{\text {eq }}, 2.6 \% \mathrm{SO}_{3}$, and $1.3 \% \mathrm{LOI}$ was utilized as a sole cementitious material.

\subsection{Mortar Bars}

Mortar bar specimens of dimensions $25.4 \times 25.4 \times 254 \mathrm{~mm}$ were prepared according to ASTM C 1260 standard (2007) which consisted of $10 \% \# 8$ sieve $(2.3 \mathrm{~mm}), 25 \% \# 16$ sieve $(1.18 \mathrm{~mm}), 25 \% \# 30$ sieve $(600 \mu \mathrm{m}), 25 \%$ $\# 50$ sieve $(300 \mu \mathrm{m}), 15 \%$ \#100 sieve $(150 \mu \mathrm{m})$. The moisture content and absorption of the graded aggregate were accounted for in determining the actual mixing water content of the mixture. Aggregate-to-cement ratio of 2.15 and water-to-cement ratio (by weight) of 0.47 were also maintained.

Four mortar bars were fabricated from a constant 7-bar batch size mixture containing each trial aggregate source. The mortars were mixed in accordance with the requirements of ASTM C 305 and molded within a total elapsed time of less than 2 minutes and 15 seconds. The mortar bars were kept in a curing room maintaining relative humidity of $100 \%$ and a temperature of $20{ }^{\circ} \mathrm{C}$ for 24 hours. The mortar bars were then demolded one at a time and their initial readings were recorded by a digital extensometer before immersing in water at $80{ }^{\circ} \mathrm{C}$ for 24 hours. After taking zero readings, the specimens were immerged in a $1.0 \mathrm{~N} \mathrm{NaOH}$ soak solution in an air-tight plastic container kept in an oven which maintained the temperature of $80 \pm 1{ }^{\circ} \mathrm{C}$. Subsequent expansion readings were measured at the ages of 3, 6, 10 and 14 days, and after that one reading per week until the immersion age was reached at 13 weeks.

\subsection{Concrete Prisms}

Concrete prisms of dimensions $75 \times 75 \times 250 \mathrm{~mm}$ from each investigated aggregate were fabricated according to the requirements of ASTM C 1293 with an exception of Type V Portland cement having a total alkali content of $1.25 \% \mathrm{Na}_{2} \mathrm{O}_{\mathrm{e}}$. An appropriate amount of $\mathrm{NaOH}$ pellet was added in the mixing water to raise cement alkali from 0.84 to $1.25 \% \mathrm{Na}_{2} \mathrm{O}_{\mathrm{e}}$. The moisture content and absorption of the graded aggregates were included to determine the design water-to-cement ratio. A constant volume of $0.009 \mathrm{~m}^{3}\left(0.30 \mathrm{ft}^{3}\right)$ concrete containing each aggregate group was used to prepare three prisms. The specimens were then moist cured for 24 hours, and placed in water at $80^{\circ} \mathrm{C}$ for 24 hours after which zero readings were recorded with a digital extensometer. They were then fully submerged in a $1 \mathrm{~N} \mathrm{NaOH}$ solution in an air-tight plastic containers held in an oven with the temperature of $80 \pm 1{ }^{\circ} \mathrm{C}$. The expansion readings of the specimens were recorded once per week until an immersion age of 13 weeks had reached. 


\section{Results and Discussions}

\subsection{ASR Classification Based on Aggregate's Types}

Whole rock analyses were conducted to determine the chemical compositions of the aggregate groups. The aggregates were then identified by their rock type according to the geological nomenclature. The results are presented in Table 2. Based on the results presented in Table 1, the potential ASR of the aggregates is documented in Table 2.

Table 2. Aggregate identification, rock type, and potential alkali-silica reactivity

\begin{tabular}{|c|c|c|c|c|c|c|c|c|c|c|}
\hline \multirow{2}{*}{$\begin{array}{l}\text { Agg. } \\
\text { Id. }\end{array}$} & \multicolumn{8}{|c|}{ Compositions (\%) } & \multirow{2}{*}{ Rock Type } & \multirow{2}{*}{$\begin{array}{c}\text { Potential ASR } \\
\text { reactivity }\end{array}$} \\
\hline & $\mathrm{SiO}_{2}$ & $\mathrm{Al}_{2} \mathrm{O}_{3}$ & $\mathrm{Fe}_{2} \mathrm{O}_{3}$ & $\mathrm{CaO}$ & $\mathrm{MgO}$ & $\mathrm{Na}_{2} \mathrm{O}$ & $\mathrm{K}_{2} \mathrm{O}$ & LIO & & \\
\hline AG-1 & 0.74 & 0.03 & 0.12 & 30.74 & 21.24 & $<0.01$ & 0.03 & 46.5 & Dolomite & I \\
\hline AG-2 & 17.19 & 1.22 & 0.28 & 43.40 & 1.49 & 0.24 & 0.39 & 35.6 & Limestone & $\mathrm{R}$ \\
\hline AG-3 & 13.50 & 0.40 & 0.29 & 32.55 & 13.09 & 0.03 & 0.14 & 39.4 & Dolomite-limestone & $\mathrm{R}$ \\
\hline AG-4 & 1.83 & 0.38 & 0.28 & 30.60 & 20.18 & 0.03 & 0.16 & 45.4 & Dolomite & I \\
\hline AG-5 & 63.09 & 11.50 & 3.48 & 6.92 & 1.97 & 2.34 & 3.28 & 6.43 & Dacite & $\mathrm{R}$ \\
\hline AG-6 & 60.82 & 15.89 & 5.37 & 4.34 & 2.49 & 3.57 & 3.73 & 2.14 & Andesite & $\mathrm{R}$ \\
\hline AG-7 & 10.91 & 0.66 & 0.24 & 41.00 & 6.65 & 0.05 & 0.29 & 39.4 & Limestone & I \\
\hline AG-8 & 56.66 & 15.83 & 5.78 & 5.33 & 3.36 & 3.60 & 3.85 & 2.88 & Basaltic-andesite & $\mathrm{R}$ \\
\hline AG-9 & 68.00 & 15.48 & 2.86 & 1.14 & 0.94 & 4.52 & 5.40 & 0.63 & Dacite & $\mathrm{R}$ \\
\hline AG-10 & 61.17 & 16.82 & 5.64 & 4.88 & 2.28 & 3.54 & 1.92 & 2.2 & Andesite & $\mathrm{R}$ \\
\hline AG-11 & 59.33 & 17.15 & 5.83 & 5.30 & 2.54 & 3.76 & 2.68 & 1.83 & Andesite & $\mathrm{R}$ \\
\hline AG-12 & 52.50 & 18.45 & 8.35 & 8.36 & 4.59 & 3.74 & 1.22 & 0.98 & Basaltic-andesite & $\mathrm{R}$ \\
\hline AG-13 & 64.14 & 17.01 & 4.20 & 4.16 & 1.76 & 4.23 & 2.54 & 0.92 & Dacite & $\mathrm{R}$ \\
\hline
\end{tabular}

I: Innocuous; R: Reactive.

\subsection{Development of Mortar Expansion and Aggregate Classifications}

Figure 1 shows the progression of mortar expansion at 2, 4, 8 and 13 weeks. As can be seen, the expansion increased with increasing test duration, and the expansion characteristics over the time varied depending on the aggregate source. The expansion development was faster and more extensive for reactive aggregates than that of the innocuous aggregates. In general, a maximum increase in expansion was observed between the first 4 weeks, and a moderate increase in expansion was noted between 4 and 8 weeks, after which the specimens expanded slowly up to the test duration of 13 weeks.

Table 3 documents ASR classifications of the aggregates based on the expansion limits of mortar bars at 2, 4 and 8 weeks. As can be seen, the ASR classifications of the thirteen aggregates were shown nearly a perfect match based on the 4- and 8-week expansion criteria, proposed by Hooton (1991), and Rogers and Hooton (1993), and those suggested by Islam (2010). However, the failure criteria at 2 weeks overestimated three aggregates (AG-2, AG-8, and AG-10) as reactive though they were considered to be innocuous by the failure criteria of extended immersion ages.

The study also revealed that the aggregates producing expansion of more than $0.15 \%$ at 2 weeks were proved to be reactive at the extended immersion ages. The mortar bars made with the AG-2 and AG-10 aggregates generating less than $0.15 \%$ expansion at 2 weeks were found to be innocuous based on failure criteria of the extended ages. Overall, the alkali-silica reactivity of the selected aggregates based on the extended immersion ages provided more consistent results than that obtained at the early immersion age of 2 weeks. 


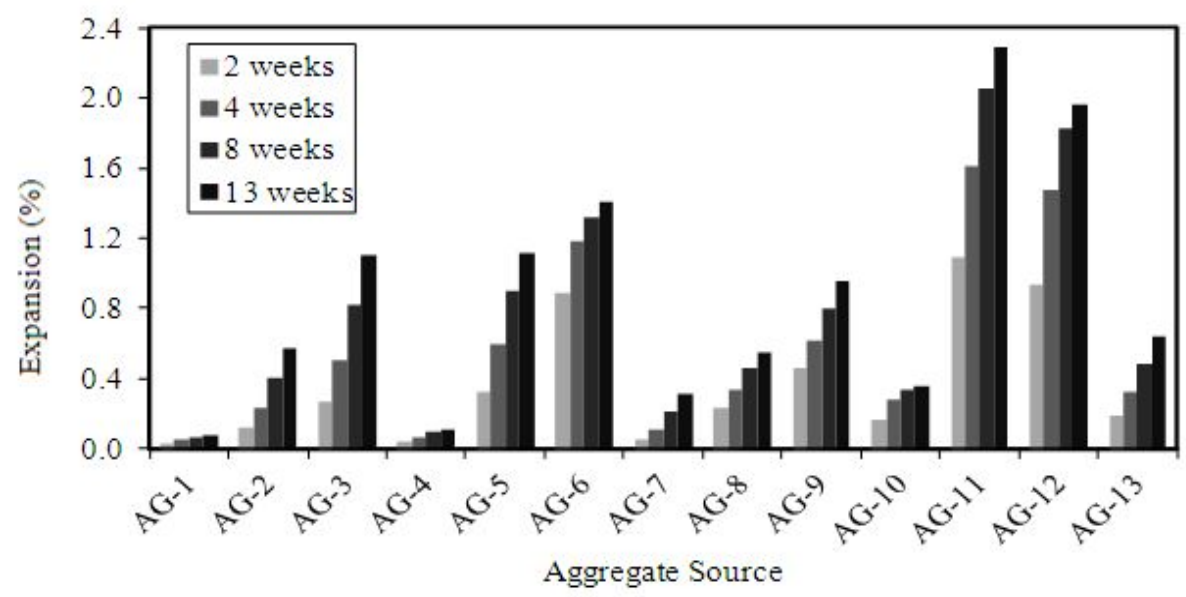

Figure 1. Mortar expansions at 2, 4, 8 and 13 weeks

Table 3. Aggregate classifications based on the limits of mortar bars

\begin{tabular}{cccccc}
\hline Agg. & 2-Week & \multicolumn{2}{c}{ 4-Week } & \multicolumn{2}{c}{8 -Week } \\
\cline { 3 - 6 } ID & $(0.10 \%)$ & $0.28 \%^{\mathrm{b}}$ & $0.33 \%^{\mathrm{c}}$ & $0.47 \%^{\mathrm{b}}$ & $0.48 \%^{\mathrm{c}}$ \\
\hline AG-1 & $\mathrm{I}$ & $\mathrm{I}$ & $\mathrm{I}$ & $\mathrm{I}$ & $\mathrm{I}$ \\
AG-2 & $\mathrm{SR}$ & $\mathrm{I}$ & $\mathrm{I}$ & $\mathrm{I}$ & $\mathrm{I}$ \\
AG-3 & $\mathrm{R}$ & $\mathrm{R}$ & $\mathrm{R}$ & $\mathrm{R}$ & $\mathrm{R}$ \\
AG-4 & $\mathrm{I}$ & $\mathrm{I}$ & $\mathrm{I}$ & $\mathrm{I}$ & $\mathrm{I}$ \\
AG-5 & $\mathrm{R}$ & $\mathrm{R}$ & $\mathrm{R}$ & $\mathrm{R}$ & $\mathrm{R}$ \\
AG-6 & $\mathrm{R}$ & $\mathrm{R}$ & $\mathrm{R}$ & $\mathrm{R}$ & $\mathrm{R}$ \\
AG-7 & $\mathrm{I}$ & $\mathrm{I}$ & $\mathrm{I}$ & $\mathrm{I}$ & $\mathrm{I}$ \\
AG-8 & $\mathrm{R}$ & $\mathrm{R}$ & $\mathrm{I}$ & $\mathrm{I}$ & $\mathrm{I}$ \\
AG-9 & $\mathrm{R}$ & $\mathrm{R}$ & $\mathrm{R}$ & $\mathrm{R}$ & $\mathrm{R}$ \\
AG-10 & $\mathrm{SR}$ & $\mathrm{I}$ & $\mathrm{I}$ & $\mathrm{I}$ & $\mathrm{I}$ \\
AG-11 & $\mathrm{R}$ & $\mathrm{R}$ & $\mathrm{R}$ & $\mathrm{R}$ & $\mathrm{R}$ \\
AG-12 & $\mathrm{R}$ & $\mathrm{R}$ & $\mathrm{R}$ & $\mathrm{R}$ & $\mathrm{R}$ \\
AG-13 & $\mathrm{SR}$ & $\mathrm{R}$ & $\mathrm{R}$ & $\mathrm{R}$ & $\mathrm{R}$ \\
\hline $\mathrm{I}$ & $\mathrm{I}$ & $\mathrm{T}$ & & \\
\hline
\end{tabular}

$\mathrm{I}=$ Innocuous; $\mathrm{SR}=$ Slowly reactive; $\mathrm{R}=$ Reactive;

${ }^{a}$ Aggregates are classified as I, SR and HR based on ASTM C 1260;

${ }^{\mathrm{b}}$ Aggregates are classified as I and R based on the expansion limits suggested by Islam (2010);

${ }^{c}$ Aggregates are classified as I and R based on the failure criteria proposed by Hooton (1991) and Rogers and Hooton (1993).

The cracks seen on the exterior of mortar bars were carefully investigated. Figures 2 and 3 show the mortar bars prepared with innocuous and highly reactive aggregates, respectively. The specimens prepared with the innocuous aggregate groups illustrated no noticeable cracks even at the extended test duration of 13 weeks (Figure 2). However, the specimens prepared with the highly reactive aggregates showed severe cracks (map cracks) as depicted in Figure 3. For the reactive aggregates, tiny cracks were developed on the outer surface of mortar bars at early age due to the tension exerted by the ASR gel. Further alkali-silica reactions took place in the mortar bars with an increase in test duration, which resulted in an increase in expansion and surface cracking. 


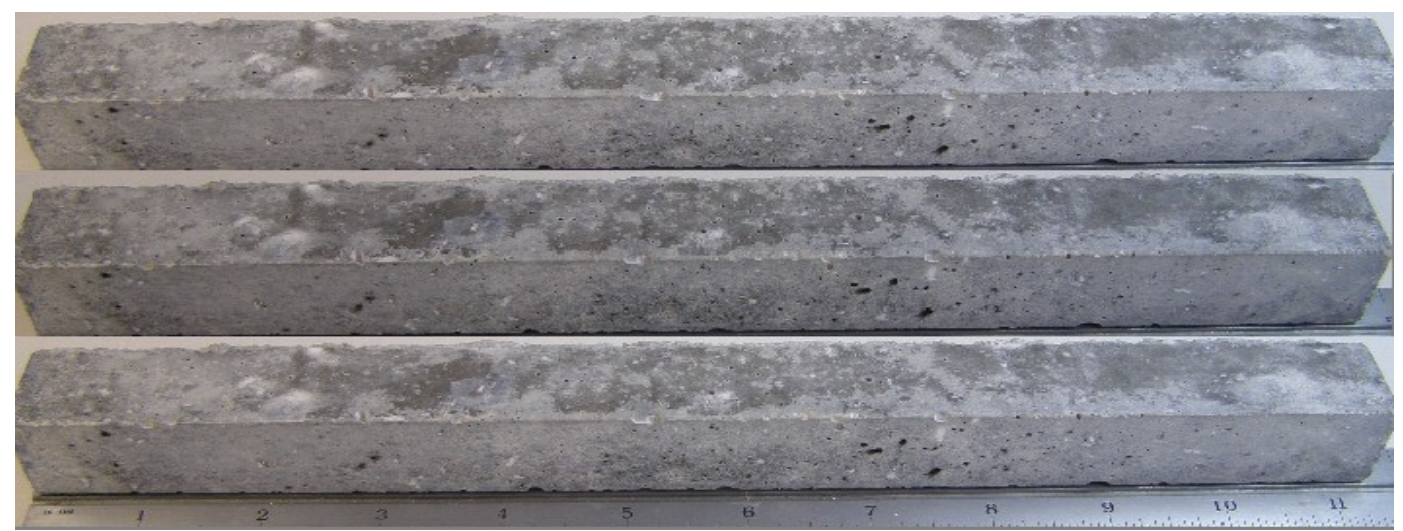

Figure 2. Mortar bars made with the innocuous aggregate (AG-7)

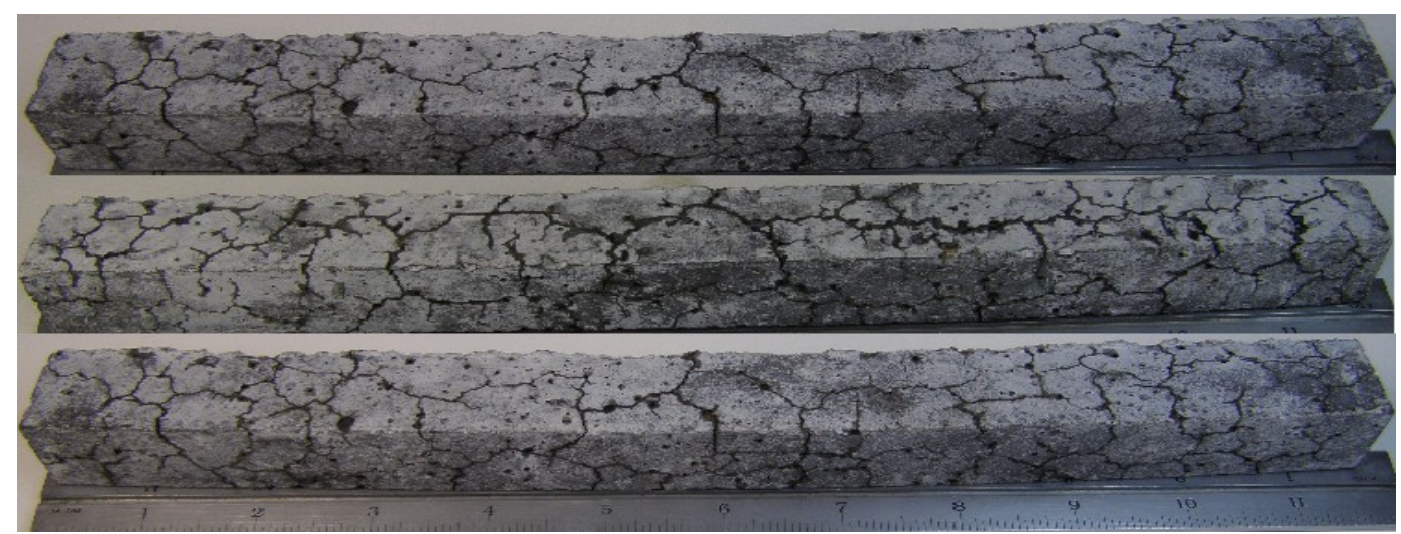

Figure 3. Mortar bars made with highly reactive aggregate (AG-12)

\subsection{Development of Prisms Expansions and Aggregate Classifications}

The expansions of alkali-cured prisms made with the thirteen aggregate groups over the test duration of 13 weeks are illustrated in Figure 4. As can be seen, the progression in expansion varied primarily depending on the aggregate type. For instance, the alkali-cured prisms made with the AG-1, AG-4, and AG-10 aggregate groups expanded very slowly followed by groups of AG-7 and AG-8. For the remaining nine aggregates, the ASR-induced expansion increased progressively with an increase in the immersion age. Figure 4 also demonstrates that the expansion deviation among the trial aggregates was small at early age, and became more diverged with the test duration. At the extended immersion age of 13 weeks, the variation in the ASR-induced expansions became substantial among the investigated aggregates. The high concentration $(1 \mathrm{~N})$ of alkali solution $(\mathrm{NaOH})$ raised alkali content of pore solution in the prisms, which resulted in excess expansions for most aggregates. Depending on composition, physical characteristics and/or crystalline structure of aggregate, some aggregates expanded rapidly at the early age, while others grew slowly with an increase in immersion age. 


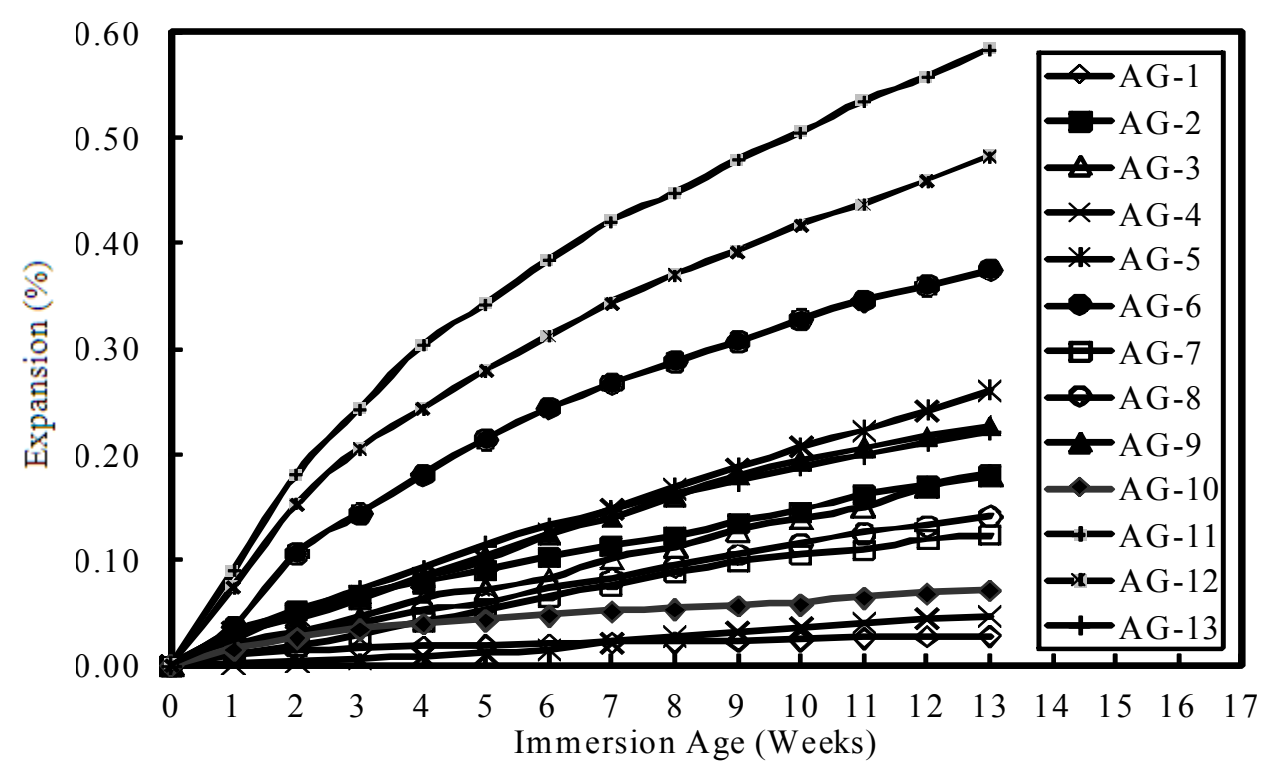

Figure 4. Expansion of alkali-cured prisms at $80{ }^{\circ} \mathrm{C}(\mathrm{C} 1293 \mathrm{M} 1)$

\subsection{Determination of the Failure Criteria of Alkali-Cured Concrete Prisms}

Dimension of test specimens play an important role on the development of expansion over time. The mortar bar and concrete prism specimens exposed to the same environment (alkali concentration and temperature) did not undergo ASR at the same rate due to their size difference. The relationship between the expansion of mortar bar and that of alkali-cured prism at 4, 8 and 13 weeks was shown in Figure 5. As can be observed, a linear correlation existed between the expansion of mortar bar (EMB) and the expansion of concrete prism (ECP). The trend of the data points is represented by Equation 3. The $\mathrm{F}$ and $\mathrm{t}$ tests were performed to confirm the significance of coefficient a for the regression model. Statistical parameters for Equation 1 and the failure limits of alkali-cured concrete prisms at 4,8 , and 13 weeks are shown in Table 4 . The value of Prob(F) of 0.0 and $R^{2}$ values of 0.93-0.94 indicated that EMB and ECP were correlated well at all three test durations. Additionally, another reliable parameter for multiple regression models $\mathrm{R}_{\text {adj }}^{2}$ values, which were shown to be very close to the $\mathrm{R}^{2}$ values. The standard errors of the estimate (0.022-0.039) were the standard deviations of the residuals.

$$
y=a x
$$

Where:

$x$ and $y$ are the expansions of the alkali-cured mortar bars and concrete prisms, respectively; $a$ is the regression variable, which is the slope of ECP vs. EMB line.

Table 4 also shows the cut off points for the expansion of alkali-cured prisms to classify aggregates based on their susceptibility to alkali-silica reactivity. Aggregates producing more than $0.052 \%$ expansion at 4 weeks, $0.100 \%$ at 8 weeks, and $0.150 \%$ at 13 weeks were considered as reactive, those generating expansions below the above-mentioned threshold limits were regarded as innocuous, and those remained between these two limits could be labeled as slowly reactive aggregates. 


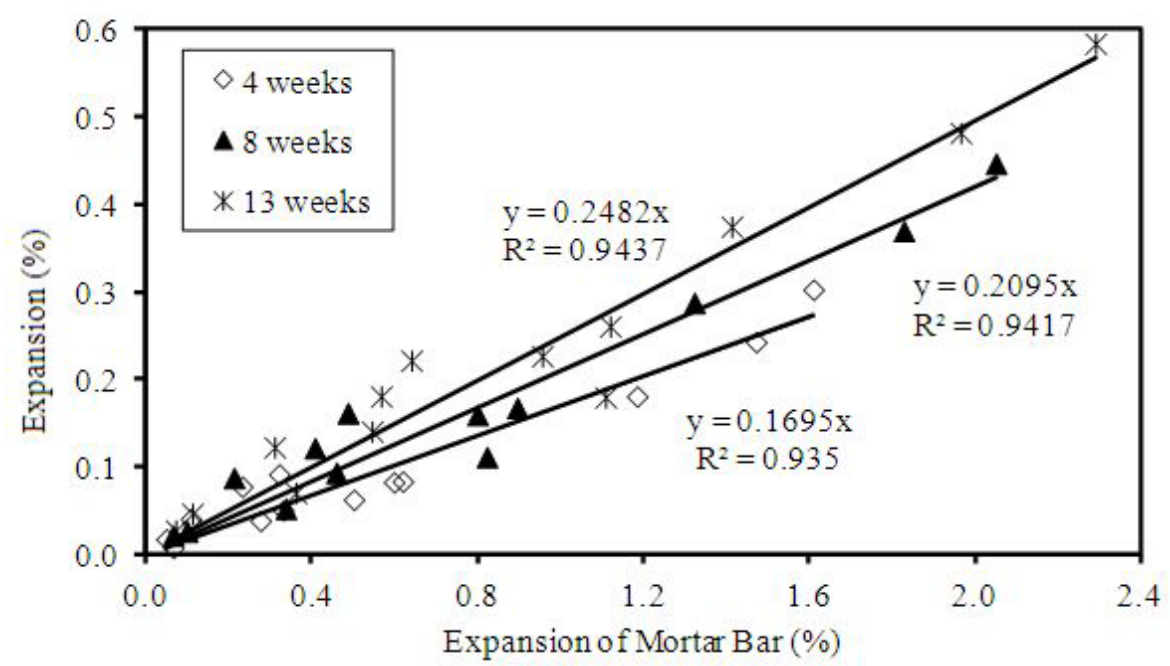

Figure 5. The expansion of mortar bars vs. the expansion of concrete prisms

Table 4. Statistical parameters for Equation 3, and the failure limits of concrete prisms at various ages

\begin{tabular}{cccc}
\hline Variables & \multicolumn{3}{c}{ ECP vs. EMB at Immersion Age } \\
\cline { 2 - 4 } & 4 weeks & 8 weeks & 13 weeks \\
\hline Value of Regression Parameter a & 0.1801 & 0.2095 & 0.2483 \\
Prob(t) of a & 0.0000 & 0.0000 & 0.0000 \\
Prob(F) & 0.0000 & 0.0000 & 0.0000 \\
Standard Error & 0.0227 & 0.0315 & 0.0396 \\
$\mathrm{R}^{2}$ & 0.935 & 0.942 & 0.944 \\
$\mathrm{R}^{2}{ }_{\text {adj }}$ & 0.930 & 0.937 & 0.939 \\
Expansion limits of mortar bars (\%) & $0.28^{\mathrm{a}}$ & $0.48^{\mathrm{a}}$ & $0.60^{\mathrm{c}}$ \\
& $0.33^{\mathrm{b}}$ & $0.47^{\mathrm{b}}$ & \\
Expansion limits of concrete prisms (\%) & $0.052^{\mathrm{d}}$ & $0.100^{\mathrm{d}}$ & 0.150 \\
\hline
\end{tabular}

${ }^{\mathrm{a}}$ Proposed by Islam (2010); ${ }^{\mathrm{b}}$ proposed by Hooton (1991) and Rogers and Hooton (1993); ${ }^{\mathrm{c}}$ extrapolated the failure criteria of $0.10 \%$ at 2 weeks, $0.28 \%$ at 4 weeks, and $0.48 \%$ at 8 weeks; ${ }^{\mathrm{d}}$ expansion limit of alkali-cured prisms evaluated from the expansion limits of mortar bar suggested by Islam (2010); ${ }^{\mathrm{e}}$ expansion limit of alkali-cured prisms evaluated from the expansion limits of mortar bar proposed by Rogers (1991), and Hooton and Rogers (1993).

Table 5 documents the ASR classifications of the aggregates based on the previously suggested 4-week failure criteria and the proposed expansion limits of the alkali-cured prisms at $80^{\circ} \mathrm{C}$ at the ages of 4,8 and 13 weeks. As can be seen, of the thirteen aggregates, the 4-week failure criteria resulted in only three innocuous aggregates (AG-1, AG-4, AG-7). It should be noted that the ASR classifications of the thirteen aggregates matched perfectly based on the proposed expansion limits of this study at the ages of 4,8 and 13 weeks. The three suggested failure limits resulted in identifying five aggregates (AG-1, AG-4, AG-8, AG-7 and AG-10) as innocuous, and the remaining eight aggregates as reactive. The proposed failure limits of $0.052 \%$ at 4 weeks, $0.10 \%$ at 8 weeks and $0.15 \%$ at 13 weeks proved to produce for more consistent results than those generated by the 4 -week failure limit of $0.04 \%$ reported by Fournier, Bildeau, and Malhorta (1994) at the early immersion age of 4 weeks. 
Table 5. Aggregate classifications based on the failure criteria of alkali-cured prisms

\begin{tabular}{cccccc}
\hline & \multicolumn{2}{c}{4 -Week } & & & \\
Agg. ID & $0.040 \%^{\mathrm{a}}$ & $0.05 \%^{\mathrm{b}}$ & -Week $(0.100 \%)^{\mathrm{b}}$ & 13-Week $(0.150 \%)^{\mathrm{b}}$ & ASR Type \\
\cline { 2 - 4 } AG-1 & $\mathrm{I}$ & $\mathrm{I}$ & $\mathrm{I}$ & $\mathrm{I}$ & $\mathrm{I}$ \\
AG-2 & $\mathrm{R}$ & $\mathrm{R}$ & $\mathrm{R}$ & $\mathrm{R}$ & $\mathrm{R}$ \\
AG-3 & $\mathrm{R}$ & $\mathrm{R}$ & $\mathrm{R}$ & $\mathrm{R}$ & $\mathrm{R}$ \\
AG-4 & $\mathrm{I}$ & $\mathrm{I}$ & $\mathrm{I}$ & $\mathrm{I}$ & $\mathrm{I}$ \\
AG-5 & $\mathrm{R}$ & $\mathrm{R}$ & $\mathrm{R}$ & $\mathrm{R}$ & $\mathrm{R}$ \\
AG-6 & $\mathrm{R}$ & $\mathrm{R}$ & $\mathrm{R}$ & $\mathrm{R}$ & $\mathrm{R}$ \\
AG-7 & $\mathrm{R}$ & $\mathrm{I}$ & $\mathrm{I}$ & $\mathrm{I}$ & $\mathrm{I}$ \\
AG-8 & $\mathrm{R}$ & $\mathrm{I}$ & $\mathrm{I}$ & $\mathrm{I}$ & $\mathrm{I}$ \\
AG-9 & $\mathrm{R}$ & $\mathrm{R}$ & $\mathrm{R}$ & $\mathrm{R}$ & $\mathrm{R}$ \\
AG-10 & $\mathrm{R}$ & $\mathrm{I}$ & $\mathrm{I}$ & $\mathrm{I}$ & $\mathrm{I}$ \\
AG-11 & $\mathrm{R}$ & $\mathrm{R}$ & $\mathrm{R}$ & $\mathrm{R}$ & $\mathrm{R}$ \\
AG-12 & $\mathrm{R}$ & $\mathrm{R}$ & $\mathrm{R}$ & $\mathrm{R}$ & $\mathrm{R}$ \\
AG-13 & $\mathrm{R}$ & $\mathrm{R}$ & $\mathrm{R}$ & $\mathrm{R}$ & $\mathrm{R}$ \\
\hline
\end{tabular}

$\mathrm{I}=$ Innocuous; R = Reactive; ${ }^{a}$ failure limit suggested by Fournier et al., 1994; ${ }^{\mathrm{b}}$ failure limits proposed in this study.

The surface of prism specimens was evaluated for the ASR-induced cracks. Figures 6 and 7 illustrate the 13-week alkali-cured prisms prepared with innocuous and reactive aggregates as determined by the proposed 4-, 8-, and 13-week expansion limits. The specimens containing innocuous aggregate (AG-1) showed no visible cracks even at 13 weeks (Figure 6), whereas reactive aggregates experienced severe cracks (map cracks) (Figure 7). It was also observed that cracks were formed on the outer surface of the prisms and the reactive aggregates were forced to pop out due to the pressure exerted by ASR-induced expansion.

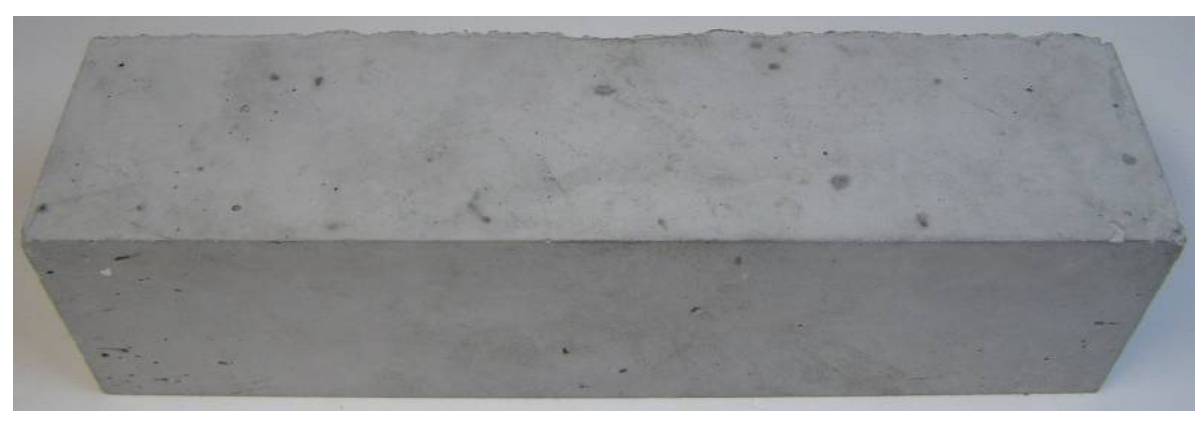

Figure 6. Prism made with innocuous aggregate (AG-1 Aggregate) 


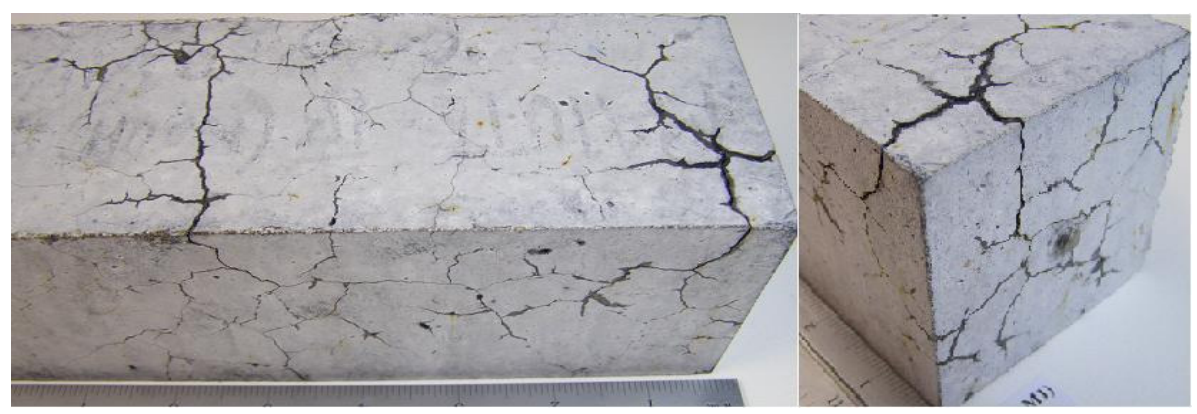

a)

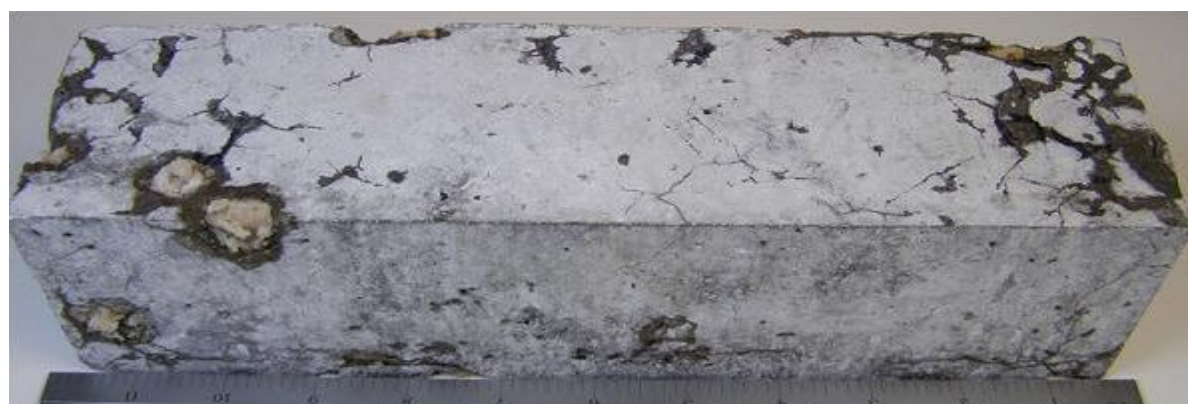

b)

Figure 7. Prisms made with reactive aggregates of a) AG-11 and b) AG-6

\subsection{ASR Kinetic Model for the Alkali-Cured Prisms}

The expansion data of alkali-cured prisms over the test durations of 4, 8 and 13 weeks was fitted with Equation 2 , and the values of Avrami exponent $(M)$ and natural log of Avari rate constant $(\ln (k))$ for each aggregate were determined. The statistical parameter and their significance for Equation 2 were examined. The coefficient of determination of the kinetic model for all aggregate groups $\left(\mathrm{R}^{2}>95 \%\right)$ implied that more than $95 \%$ of the variability of dependent variable was explained by the equation. Additionally, $\mathrm{R}_{\text {adj }}^{2}$ values were shown to be very close to the $\mathrm{R}^{2}$ values. Moreover, the $\mathrm{p}$-value of the model for each aggregate group is shown to be very low, and $\operatorname{Prob}(\mathrm{F})$ of the suggested model for all trial aggregates were shown as low as 0.0000 .

Figure 8 shows that the relationships of $\ln (k) / M$ values at the test durations of 4,8 and 13 weeks. As can be seen, a linear correlation with $\mathrm{R}^{2}$ values of 0.97 and 0.96 existed between the $\ln (k) / M$ values at 4 weeks and those obtained at the immersion ages of 8 and 13 weeks, respectively. The slopes of the both linear regression lines are 1.03, which is nearly equal to 1.0 , indicated that the $\ln (k) / M$ values were nearly identical regardless of the test duration.

The 4-, 8-, and 13-week expansions of alkali-cured prisms were correlated with $\ln (k)$ and $M$ of the companion aggregate groups at the corresponding immersion ages, and no definite relationship was observed. However, the ratio of $\ln (k)$ and $M[=\ln (k) / M]$ was found to be strongly correlated with the expansions at 8 , and 13 weeks. Since the expansion of alkali-cured prisms at early age of 4 weeks was progressive (i.e. not stable), the interaction between the $\ln (k) / M$ and the 4-week expansions did show a good association. 


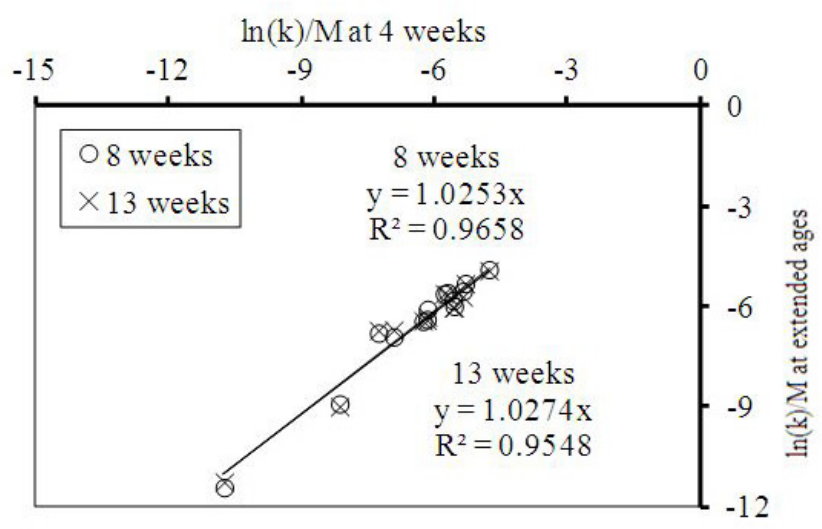

Figure 8 . The relationships of 4 -week $\ln (k) / M$ values with those obtained at 8 and 13 weeks

The trend between the prism expansions and $\ln (k) / M$ values at 13 weeks is represented by Equation 4 , and shown in Figure 9. The statistical parameters of Equation 4 were also determined. The absolute t-ratio and Prob(F) for all regression coefficients were much greater than 1.0 and in close proximity to 0.0000 , respectively. The smaller the absolute value of $\mathrm{p}$-value, the more significant the parameter and the less likely that the actual parameter value could be zero. Additionally, the coefficient of multiple determinations $\left(\mathrm{R}^{2}\right)$ was shown to be $86 \%$, and the adjusted $\mathrm{R}^{2}$ value was very close to $\mathrm{R}^{2}$. Using Equation 4 and the 13 -week expansion limit of alkali-cured prisms $(0.15 \%)$, the failure limit of $\ln (k) / M$ was determined to be -6.4 . This value serves a threshold to classify aggregates into reactive and innocuous groups. That is to say that aggregates having less than the above-mentioned $\ln (k) / M$ value can be considered as innocuous, and those generating a higher value can be regarded as reactive.

In the case of 8 -week test duration, the failure criterion of $\ln (k) / M$ was also determined using a similar approach to those used for the expansion of alkali-cured prisms at 13 weeks. Equation 5 represents best fit relationship between 8 -week prism expansions and $\ln (\mathrm{k}) / M$. The statistical analysis showed that the model was valid since the residuals were nearly around zero line, and the model was accurate as it generated a $\mathrm{R}^{2}$ value of $78 \%$. When 8 -week expansion limit of alkali-cured prisms of $0.10 \%$ was used in Equation 5, the 8-week failure criterion as defined by $\ln (k) / M$ remained similar to that found for alkali-cured expansion at 13 weeks (-6.4). This indicated that failure criteria obtained from ASR kinetic model was independent on immersion age. As such, the proposed failure limit of $\ln (k) / M$ offers a good prediction in classifying alkali-silica reactivity of trial aggregates even at the early age of 4 weeks.

$$
\begin{aligned}
& \ln (k) / M=\log \left(3.67 \times 10^{-4}+1.366 \times 10^{-2} * \operatorname{Exp}\right) \\
& \ln (k) / M=\log \left(4.355 \times 10^{-4}+2.07 \times 10^{-2} * \operatorname{Exp}\right)
\end{aligned}
$$

Where: Exp is the alkali-cured expansions.

\subsection{ASR Classifications of Investigated Aggregates}

Table 6 shows the ASR classifications of the investigated aggregate groups based on the aggregate type, expansion limits of mortar bars, proposed expansion limits of alkali-cured prisms, and failure criteria of ASR kinetic. As can be seen in Table 6 , the limit of $\ln (k) / M$ of -6.4 was very effective in separating the aggregate groups into reactive and innocuous at the ages of 4,8 , and 13 weeks. The proposed expansion limits of alkali-cured prisms were able to classify the trial aggregate groups consistently at all 3 immersion ages. Moreover, there were good agreements in the ASR classifications obtained from the failure limits mortar bars at the extended ages of 4 and 8 weeks, and alkali-cured prisms and ASR kinetic model were nearly in perfect agreement. 


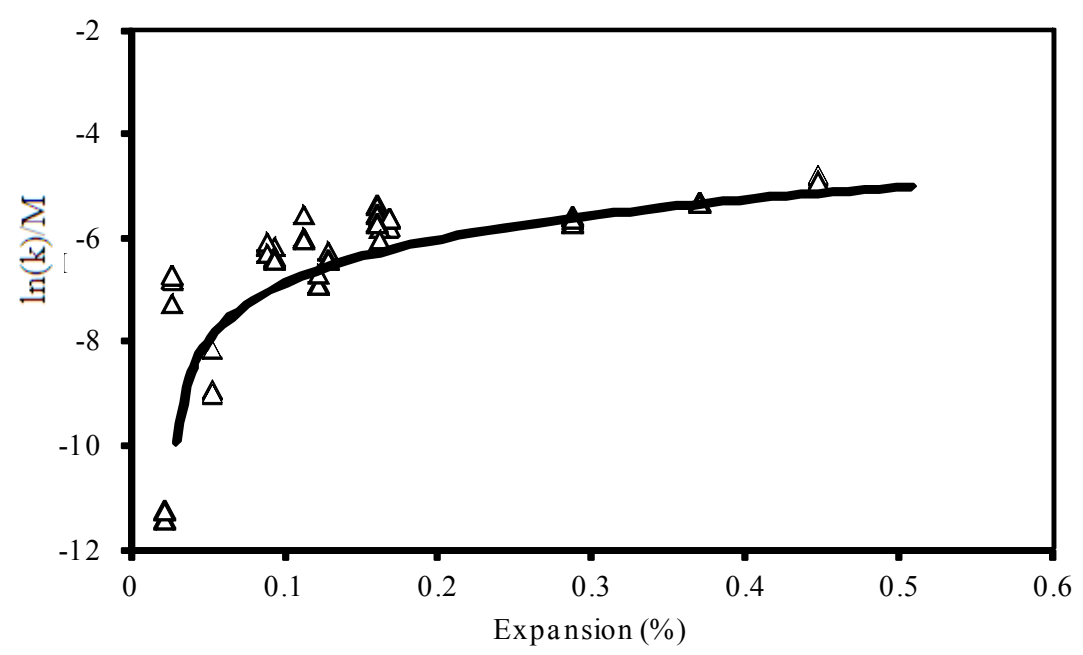

Figure 9. Relationship of prism (alkali-cured) expansions and $\ln (k) / M$ at 13 weeks

Table 6. ASR classifications based on the proposed limits of mortar bars, alkali-cured prisms and ASR kinetic

\begin{tabular}{|c|c|c|c|c|c|c|c|c|c|c|}
\hline \multirow{3}{*}{$\begin{array}{c}\begin{array}{c}\text { Agg. } \\
\text { ID }\end{array} \\
\left(\mathrm{ASR}^{\mathrm{a}}\right)\end{array}$} & \multicolumn{4}{|c|}{ Mortar bar test } & \multicolumn{3}{|c|}{ Alkali-cured prisms } & \multicolumn{3}{|c|}{ ASR Kinetics $[\ln (k) / M]$} \\
\hline & Rock & 2 & 4 & 8 & 4 & 8 & 13 & 4 & 8 & 13 \\
\hline & Type & weeks & weeks & weeks & weeks & weeks & weeks & weeks & weeks & weeks \\
\hline AG-1 (I) & I & I & I & I & I & I & I & I & I & I \\
\hline AG-2 (I) & $\mathrm{R}$ & SR & I & I & $\mathrm{R}$ & $\mathrm{R}$ & $\mathrm{R}$ & I & I & I \\
\hline AG-3 (R) & $\mathrm{R}$ & $\mathrm{R}$ & $\mathrm{R}$ & $\mathrm{R}$ & $\mathrm{R}$ & $\mathrm{R}$ & $\mathrm{R}$ & $\mathrm{R}$ & $\mathrm{R}$ & $\mathrm{R}$ \\
\hline AG-4 (I) & I & I & I & I & I & I & I & $\mathrm{R}$ & I & I \\
\hline AG-5 (R) & $\mathrm{R}$ & $\mathrm{R}$ & $\mathrm{R}$ & $\mathrm{R}$ & $\mathrm{R}$ & $\mathrm{R}$ & $\mathrm{R}$ & $\mathrm{R}$ & $\mathrm{R}$ & $\mathrm{R}$ \\
\hline AG-6 (R) & $\mathrm{R}$ & $\mathrm{R}$ & $\mathrm{R}$ & $\mathrm{R}$ & $\mathrm{R}$ & $\mathrm{R}$ & $\mathrm{R}$ & $\mathrm{R}$ & $\mathrm{R}$ & $\mathrm{R}$ \\
\hline AG-7 (I) & I & I & I & I & I & I & I & I & $\mathrm{R}$ & $\mathrm{R}$ \\
\hline AG-8 (R) & $\mathrm{R}$ & $\mathrm{R}$ & $\mathrm{R}$ & I & $\mathrm{R}$ & $\mathrm{R}$ & I & $\mathrm{R}$ & $\mathrm{R}$ & I \\
\hline AG-9 (R) & $\mathrm{R}$ & $\mathrm{R}$ & $\mathrm{R}$ & $\mathrm{R}$ & $\mathrm{R}$ & $\mathrm{R}$ & $\mathrm{R}$ & $\mathrm{R}$ & $\mathrm{R}$ & $\mathrm{R}$ \\
\hline AG-10 (R) & $\mathrm{R}$ & SR & I & I & I & I & I & $\mathrm{R}$ & I & I \\
\hline AG-11 (R) & $\mathrm{R}$ & $\mathrm{R}$ & $\mathrm{R}$ & $\mathrm{R}$ & $\mathrm{R}$ & $\mathrm{R}$ & $\mathrm{R}$ & $\mathrm{R}$ & $\mathrm{R}$ & $\mathrm{R}$ \\
\hline AG-12 (R) & $\mathrm{R}$ & $\mathrm{R}$ & $\mathrm{R}$ & $\mathrm{R}$ & $\mathrm{R}$ & $\mathrm{R}$ & $\mathrm{R}$ & $\mathrm{R}$ & $\mathrm{R}$ & $\mathrm{R}$ \\
\hline AG-13 (R) & $\mathrm{R}$ & SR & $\mathrm{R}$ & $\mathrm{R}$ & $\mathrm{R}$ & $\mathrm{R}$ & $\mathrm{R}$ & $\mathrm{R}$ & $\mathrm{R}$ & $\mathrm{R}$ \\
\hline
\end{tabular}

I: innocuous; R: Reactive; SR: Slowly Reactive; ${ }^{a}$ based on aggregate mineralogy.

\section{Conclusions}

The findings of this research study can be summarized below:

a) Unlike the previously suggested 4 -week failure criterion of $0.04 \%$, the proposed expansion limits of alkali-cured prisms of $0.052 \%$ at 4 weeks, $0.10 \%$ at 8 weeks, and $0.15 \%$ at 13 weeks proved to be effective to produce consistent ASR classification of the investigated aggregates.

b) Using ASR kinetic model, the proposed failure criterion of $\ln (k) / M$ of -6.40 , was a good predictor of ASR classifications of the trial aggregates that conformed with the results obtained by the aggregate 
type, the previously suggested expansion limits of mortar bars at the extended ages ( 28 and 56 weeks), and the proposed failure criteria of alkali-cured prisms at 4-, 8-, and 13-week immersion ages.

c) Evaluations of alkali-silica reactivity of the investigated through aggregate type, extended failure limits of mortar bars, proposed expansion limits of alkali-cured prisms, and proposed failure criteria of ASR kinetic produced consistent results. Since alkali-silica reactivity depended on many factors, a combination of these methods can be viewed as a reliable indicator to predict aggregate potential for deleterious alkali-silica reactivity.

\section{Acknowledgements}

The authors acknowledge Nevada Department of Transportation for financial support of this investigation. Materials contributions by the aggregate and cement producers are also acknowledged.

\section{References}

ACI Committee 221. (1998). State-of-the-Art Report on Alkali-Aggregate Reactivity. ACI 221-1R-98, American Concrete Institute, Farmington Hills, MI, 31.

Adam, J. T. (2004). Potential concrete aggregate reactivity in northern Nevada (Master's thesis paper). UMI Microform Number: 1420180, University of Nevada, Reno, NV.

ASTM Standard C1260. (2007). Standard Test Method for Potential Alkali Reactivity of Aggregates (Mortar-Bar Method). ASTM International, West Conshohocken, PA.

ASTM Standard C1293. (1995). Standard test method for concrete aggregates by determination of length change of concrete due to alkali-silica reaction. ASTM International, West Conshohocken, PA.

Berra, M., Mangialardi, T., \& Paolini, A. E. (1998). Testing natural sands for the alkali reactivity with the ASTM C 1260 mortar bar expansion method, Journal of the Ceramic Society of Japan, 106, 237-241. http://dx.doi.org/10.2109/jcersj.106.237

Bérubé, M.-A., \& Frenette, J. (1994). Testing concrete for AAR in $\mathrm{NaOH}$ and $\mathrm{NaCl}$ solutions at $38^{\circ} \mathrm{C}$ and $80^{\circ} \mathrm{C}$. Cement and Concrete Composites, 16(3), 189-198. http://dx.doi.org/10.1016/0958-9465(94)90016-7

DeMerchant, D. P., \& Soles, J. A. (1993). CANMET research on alkali-aggregate reactivity in New Brunswick. International workshop on alkali-aggregate reactions in concrete: occurrences, testing, and control, CANMET-EMR, Ottawa, Canada, 35.

Deng, M., Han, S. F., Lu, Y. N., Lan, X. H., Hu, Y. L., \& Tang, M. S. (1993). Deterioration of concrete structures due to alkali-dolomite reaction in China. Cement and Concrete Research, 23, 1040-1046. http://dx.doi.org/10.1016/0008-8846(93)90163-4

Folliard, K. J., Ideker, J., Thomas, M. D. A., \& Fournier, B. (2005). Assessing aggregate reactivity using the accelerated concrete prism test. Draft Report-Prepared for ICAR, Retrieved from http://aftre.nssga.org/Symposium/2004-12.pdf.

Folliard, K. J., Thomas, M. D. A., Fournier, B., Kurtis, K. E., \& Ideker, J. H. (2006). Interim Recommendations for the Use of Lithium to Mitigate or Prevent Alkali-Silica Reaction (ASR). Report No. FHWA-HRT-06-073, Federal Highway Administration, McLean, VA, 94.

Fournier, B., Bilodeau, A., \& Malhotra, V. M. (1994). Effectiveness of high-volume fly concrete in controlling expansion due to Alkali-Silica Reaction, 721-756.

Fournier, B., Nkinamubanzi, P. C., \& Chevrier, R. (1994). Comparative field and laboratory investigations on the use of supplementary cementing materials to control alkali-silica reaction in concrete. Proceedings of the Twelfth International Conference Alkali-Aggregate Reaction in Concrete, Beijing, China, 528-537.

Grattan-Bellew, P. E. (1990). Canadian experience with mortar bar rapid tests for AAR. Canadian developments in testing concrete aggregates for alkali-aggregate reaction, Ministry of Transportation of Ontario, Downsview, Canada, Report EM-92, 17-34.

Hobbs, W. D. (1988). Alkali-silica reaction in concrete, Thomas Telford, London. http://dx.doi.org/10.1680/aric.13179

Hooton, R. D. (1991). New aggregates alkali-reactivity test methods. Ministry of Transportation, Ontario, Research Report MAT-91-14, 54. 
Hooton R. D., \& Rogers, C. A. (1993). Development of the NBRI rapid mortar bar test leading to its use in North $\begin{array}{lllll}\text { America. Construction and Building } & \text { Materials, } & 7(3), & \text { 145-148. }\end{array}$ http://dx.doi.org/10.1016/0950-0618(93)90051-D

Ikeda, T., Kawabata, Y., Hamada, H., \& Sagawa, Y. (2008). Alkali-silica reactivity of andesite in $\mathrm{NaCl}$ saturated solution. Proceedings of the International Conference on Durability of Concrete Structures, 1, 563-569.

Islam, M. S. (2010). Performance of Nevada's aggregates in alkali-aggregate reactivity of Portland cement concrete. Doctoral Dissertation, University of Nevada, Las Vegas, NV, 362.

Islam, M. S., \& Ghafoori, N. (2009). Evaluation of alkali-silica reactivity using aggregate mineralogy and expansion tests. Proceedings of Challenges Opportunities and Solutions in Structural Engineering and Construction, 467-472.

Islam, M. S., \& Ghafoori, N. (2011). Comparison of concrete expansion and stiffness due to alkali-silica reactivity. Proceedings of Concrete Solution series (The $4^{\text {th }}$ International Conference on Concrete Repair), Dresden, Germany, 243-250.

Jensen, V. (1993). Alkali-aggregate reaction in Southern Norway. Doctoral Dissertation, Division of Geology and Mineral Re-sources Engineering, The Norwegian, Institute of Technology, University of Trondheim.

Jin, W. (1998). Alkali-Silica Reaction in Concrete with Glass Aggregate - a Chemo-Physico-Mechanical Approach (Ph.D Dissertation). Columbia University, New York, NY, 154.

Johnston, D. P. (1994). Interpretation of accelerated test method ASTM P214 test results. Transportation Research Record. 1458, 129-134.

Johnston, D., Stokes, D., \& Surdahl, R. (2000). A kinetic-based method for predicting ASTM C 1260. Cement, Concrete, and Aggregates, 22(2), 142-149. http://dx.doi.org/10.1520/CCA10474J

Johnston, D., Stokes, D., Fournier, B., \& Surdahl, R. (2004). Kinetic characteristics of ASTM C 1260 testing and ASR-induced concrete damage. The $12^{\text {th }}$ International Conference on Alkali-Aggregate Reaction in Concrete, Beijing, China, 338-346.

Korkanç, M., \& Tuğrul, A. (2005). Evaluation of selected bas-alts from the point of alkali-silica reactivity. Cement and Concrete Research, 3(3), 505-512. http://dx.doi.org/10.1016/j.cemconres.2004.06.013

Lane, D. S. (1994). Alkali-Silica Reactivity in Virginia. Virginia Transportation Research Council. Final Report No. VTRC 94-R17, Virginia Transportation Research Council, Charlottesville, VA.

Malvar, J., \& Lenke, L. R. (2006). Efficiency of fly ash in mitigating alkali-silica reaction based on chemical composition, ACI Materials Journal, 103(5), 319-326.

McCoy, W. J., \& Caldwell, A. G. (1951). A new approach to inhibiting alkali-aggregate expansion. Journal of the American Concrete Institute, 47, 693-706.

Ohama, Y., Demura, K., \& Kakegawa, M. (1989). Inhibiting alkali-aggregate reaction with chemical admixtures. Proceedings of the 8th International Conference on Alkali-Aggregate Reaction, K. Okada, S. Nishibayashi, \& M. Kawamura (Ed.), Kyoto, Japan, 253-258.

Rogers, C. A. (1993). Alkali-Aggregate Reactivity in Canada. Cement and concrete composites, 15, 13-19. http://dx.doi.org/10.1016/0958-9465(93)90035-8

Rogers, C. A., \& Hooton, R. D. (1991). Reduction in mortar and concrete expansion with reactive aggregates due to alkali leaching. Cement, Concrete and Aggregates, 13(1), 42-49. http://dx.doi.org/10.1520/CCA10548J

Stark, D. (2006). Alkali-Silica Reaction in Concrete. Significance of tests and properties of concrete and concrete-making materials (ASTM STP 169D), ASTM, West Conshohocken, PA, 401-409. http://dx.doi.org/10.1520/STP37752S

Stark, D., Morgan, B., Okamoto, P., \& Diamond, S. (1993). Eliminating or minimizing alkali-silica reactivity. Strategic Highway Research Program. SHRP-P-343, Washington, DC, 49.

Swamy, R. N. (1992). The alkali-silica reaction in concrete. Blackie and Son Ltd., Glasgow, London. http://dx.doi.org/10.4324/9780203332641

Tauma, E. W., Fowler, D. W., \& Carrasquillo, R. L. (2001). Alkali-silica reaction in Portland cement concrete: testing methods alternatives. International Center for Aggregates Research (ICAR), Research Report ICAR-301-1f. Retrieved from http://www.engr.utexas.edu/icar/reports/301_1F/301_1Cvr.pdf 
Thomas, M. D. A., Fournier, B., Folliard, J., Ideker, J., \& Resendez, Y. (2007). The use of lithium to prevent or mitigate alkali-silica reaction in concrete pavements and structures. U.S. Department of Transportation, Publication No. FHWA-HRT-06-133, 47.

Tuthill, L. (1982). Alkali-silica reaction - 40 years later. Concrete International, 32-36. 